\title{
Spore density and root colonization by arbuscularmycorrhizal fungi in Heavy-Metal-Contaminated Soils
}

\author{
Gunwal, I. ,Sharma, K.C. , 2 andMago,P 3 \\ 1(Department of Botany, University of Rajasthan, Jaipur, Rajasthan, India) \\ 2(Department of Botany, University of Rajasthan, Jaipur, Rajasthan, India) \\ 3(Department of Botany, Sri Aurobindo College, University of Delhi, New Delhi)
}

\begin{abstract}
High concentrations of heavy metals have been shown to adversely affect the size, diversity, and activity ofmicrobial populations in soil. The aim of this work was to determine how the diversity of arbuscularmycorrhizal(AM) fungi is affected by the addition of sewage-amended sludge containing heavy metals in a long-termexperiment. Six AMF ecotypes werefound in the experimental soils, showing consistent differences with regard to their tolerance to the presenceof heavy metals. AMF ecotypes ranged from very sensitive to the presence of metals to relatively tolerant to highrates of heavy metals in soil. Total AMF spore numbers decreased with increasing amounts of heavy metals inthe soil. Mycorrhiza is a mutualistic relationship between plant roots and fungal hyphae. In order tosurvey of percentage root colonization and mycorrhizal spore density in soil, different locations in and around Delhi. Soil samplingwas carried out in June 2012 from surface to $30 \mathrm{~cm}$ depth.There was variation in the mycorrhizal colonization and spore number. Therefore, the present study revealed that the genus Glomuswas more predominant than others and Acuolosporawas least amongst therecovered AMF spores.
\end{abstract}

Keywords:Arbuscularmycorrhizalfungi;Glomus;Heavy metal;Root Colonization; Spores Number

\section{Introduction}

In recent years several studies have shown the harmful effects of metals on microbial diversity and activity in soil $(4,6,17)$. The accumulation of metals in soils at high concentrations can be due to anthropogenic activities such as the application of sewage sludge. The addition of sludge considerably increases the amount of heavy metals in soil, causing changes in soil properties which could be toxic for soil microorganisms (6). Soil microorganisms are known to play a key role in the mobilization and immobilization of metal cations, thereby changing their availability to plants (3). Arbuscularmycorrhizae (AM) are regarded as a mutualistic association in which plant provides the fungus with assimilates in exchange for mineral nutrients and water (26). AMF occur in almost all habitats and climates (2), including in disturbed soils such as those derived from mine activities (5), but soil degradation usually produces changes in the diversity and abundance of AMF populations $(13,15,16)$. In natural communities, approximately $80 \%$ of higher plants are obligatorily dependent on fungal associates and $18 \%$ typically non mycorrhizal(23). Arbuscularmycorrhizal fungi (AMF) are important component of rhizosphere microbial communitiesinnatural ecosystems, forming symbiotic associations with the majority of land plant roots (26).The AM symbiosis plays an important role in natural ecosystems as well as in agroecosystems. It has been proved that arbuscularmycorrhizae (AM) can be found in almost all sorts of soils in different tropical, mild and cold habitats (30). The fungal hyphae spread into the soil from host plant roots and improve the efficiency of nutrient uptake, such as immobile phosphate ions $(23,25)$.Today, mycorrhizal symbiosis are found associated with more than $90 \%$ of terrestrial plants, distributed in all climates and ecosystems regardless of soil type, vegetation and environmental conditions (22). Colonization is restricted to root cortex and does not enter the vascular cylinder. Spore quantification has been very useful for evaluating the level and diversity of mycorrhizas because spores are highly resistant to adverse conditions(1). It was shown that the soil mycelium of AMF was coated with a mucilaginous substance that caused soil particles to adhere together (19).

\subsection{Study area and sample collection}

\section{Materials And Methods}

Three different points (A, B and C) $10 \mathrm{~km}$ around Delhi, India (28.38N, 77.11E, $228 \mathrm{~m}$ altitude) were sampled for soil and plant while the fourth sampling point (D) is located in garden of ShriAurobindo college, Delhi. Soil and plant samples each were collected from points A, B, C (Contaminated soil) and D (Non contaminated soil) during the winter season. The climate of Delhi is semi-arid and subtropical with the mean annual rainfall of about $650 \mathrm{~mm}$. Soil and plant samples were collected from surface to $30 \mathrm{~cm}$ depth. Root samples were fixed in FAA (100 ml alcohol, $100 \mathrm{ml}$ distilled water, $13 \mathrm{ml}$ formalin and $5 \mathrm{ml}$ acetic acid) 
solution. They were transferred to laboratory and the fine roots in each sample were selected, removed and rinsed with tap water carefully for determination of root colonization. The soil samples then were air dried in the shade at laboratory temperature for spore counting.

\subsection{Counting of AMF spores}

Spores were extracted from $10 \mathrm{~g}$ rhizospheric soil of each sample by wet sieving followed by floatation centrifugation in 50\% sucrose(9). The spores were collected on a grid pattern filter paper and washed with distilled water to spread spores evenly over the entire grid. They were counted under a stereoscopic microscope $(40 \times)$. The number of spores was expressed as the mean of three replicates.

\subsection{Root colonization}

Roots were rinsed with distilled water, cleared by $10 \% \mathrm{KOH}, 30-45 \mathrm{~min}$ at $90^{\circ} \mathrm{C}$ and acidified in $1 \%$ $\mathrm{HCl}$ for 5-10 min. Then they were stained using Trypan Blue (0.05\% in lacto-glycerol) for $10 \mathrm{~min}$. They were left in lacto-glycerol at $90^{\circ} \mathrm{C}$ for $45 \mathrm{~min}$ for elimination of undesired dye particles. For quantification of AMF colonization, 70 one $\mathrm{cm}$ sections were selected randomly and left them on slides under microscope (80×) and percentage root colonization (PRC) was calculated according to Phillips and Hayman (21) procedure.

\section{Result And Discussion}

Soil was collected from different localities in and around Delhi. They were analyzed for presence of AM fungi.Five AM fungal species belonging to the genus Glomusand one belongs to genus Acoulosporawere found in rhizosphere samples from the differentlocationsand some unidentified species were also found. Total AMF spore number decreased significantly with increasing amounts of heavy metals in soil,In contaminated soil, the spore density in rhizosphere varied from 10 spores/10 g soil to 180 spores/10 $\mathrm{g}$ soil and spore density in non rhizosphere varied from 0 spores/ $10 \mathrm{gm}$ soil to 110 spores/ $10 \mathrm{gm}$ soil. In Non contaminated (Garden soil) the spore density in rhizosphere observed was 210 spores/10g soil to 115 spores/10 g soil"TABLE" 1.In contaminated soils species of arbuscularmycorrhizal fungi belonging to genus Glomus were recorded from the rhizosphere of the plants sampled, whereas in non contaminated soils, spores of two genera of arbuscularmycorrhizal fungi viz., Glomus and Acualospora (A. laevis) and some unidentified species were recovered during the study. AM is prevalent in the field plants under optimal conditions. The present study confirms similar arbuscularmycorrhizae in field grown plants under the tropical soil conditions in India. Nearly all the plants in all the soil samples studied showed mycorrhizal infection ranging from 5\% to $85 \%$ of their fine root length. This is in accordance with the results obtained by Jagpal and Mukerji (12). In the present study it was observed that root fragments of cynodon grass picked from shastri park soil (Contaminated soil)showed little infection i.e. $5 \%$ only because few spores were observed in that soil because of high contamination and roots of plants collected from Garden soil(Non contaminated soil) become heavily colonized with the VA endomycorrhizae and the \% root colonization was $98 \%$. The above mentioned observations showed that Garden soil(Non contaminated soil) had maximum no of spores in the rhizosphere soil so it showed highest degree of colonization while the shastri park soil had least no of spores and it showed lowest degree of colonization. So from the observation it is concluded that there is correlation between level of mycorrhizal infection in the roots and the spore counts of the soils around them. The more is the number of spores in the rhizosphere soil, the more is the degree of colonization.

During the present investigation it was found that the degree of VAM formation and no of spores varied in all the experimental plots studied. The colonization was lowest in plot lbecause there were no AMF inoculums spores were provided to the soil and the plot 1 was used as control plot. It was observed that colonization and spore number were increased in plot 2 at each DAS studied because the soil of the plot is inoculated with healthy spores from non contaminated soil. As compared to plot no. 2 there were less no of spores and \% root colonization in plot 3 in all the three years. This may be because the spores extracted from contaminated soil were not very healthy mostly broken, thin walled. "Fig" 1

$\mathrm{AM}$ is prevalent in the field crops under optimal conditions $(10,11,14,27)$. Nearly all plant grown in all three experimental plots showed mycorrhizal infection ranging from 5\% to $85 \%$ of their fine root length .This is in accordance with the results obtained by Jagpal and Mukerji (12). The endomycrrhizalcolononization results from three simultaneous processes viz., root growth, formation of fungal entry points on the root surface and growth of fungal hyphae along the length of the interior of root (24). Higher level of spore density in the AM inoculum results in maximum sporulation and spore germination which paves way for the massive development of hyphae and root infection by arbuscularmycorrhizal fungi compared to the lower spore density levels and un inoculated control. Enhanced arbuscularmycorrhizal infection by higher spore density had ultimately resulted in increased root surface area which recorded a maximum root volume at 5 to 6 and 10 to 12 spores g-1 of AM inoculum application. The results clearly indicated that AM colonizationand sporulation was better in T2 as compared to T3 with higher growth of host plant. The genus Glomusis the dominant mycospecies in the garden 
(rhizosphere soil) collected from different areas of Delhi, the possible reasons for the predominance of Glomus sp. are that spores of Glomusspecies have different temperature and $\mathrm{pH}$ preferences for germination (31) and Acaulosporaspecies are often associated with acidic soils $(1,18)$. The results obtained from the study suggests that the colonization percentage and number of AM spores differ with different type of soils used in the study. The soil collected from Yamuna bank has enough number of spores while the soil collected from shastri park has no spores and reason for that is the soil is contaminated with electronic waste i.e is one of the soil contamination source. This confirms that the soils of Delhi region are colonized by arbuscularmycorrhizal fungi. It is also apparent that rainy season may considered as the best season for the propagation of plants by the application of AMF as bio-inoculant.

In the present study, $6 \mathrm{AM}$ species belonging to 2 genera were identified. It is highly likely that the high AM fungal species found was due to the collection of soil samples from various habitats. Predominance of the genus Glomusin isolated species has also been reported for other metal-contaminated ecosystems, such as a $\mathrm{Cu}$ mining area of north eastern Brazil (7) and a chemical contaminated site of Northern Italy (29). The abundance of AM fungal spores ranged from 16 to 210 spores per $10 \mathrm{gm}$ of soil. Variations in AM fungal spore frequency possibly implied that differences could exist in their tolerance to heavy metals. A higher tolerance to $\mathrm{Zn}, \mathrm{Cd}$ and $\mathrm{Pb}$ of indigenous $\mathrm{AM}$ fungi from polluted soils in comparison to those of reference isolates from unpolluted soils has been reported $(32,8)$.Pawlowska(20) also found that G. constrictum, G. mosseaeand Glomussp. were dominant species in Cd contaminated soils. These five species identified (G. macrocarpum, G. mosseae, G. fasciculatum, G. fugianumand G. constrictum) should be isolated and tested in relation to their potential use as an inoculum in phytoremediation programs in these areas.(Plate 2)

The present study indicated that the first and second highest abundance of spores were recorded in the rhizosphere soil of Garden and Yamuna soil mainly for Glomus.sp with 210 spores per 10 gm of soil, respectively. Secondly, it is known that heavy metals can delay, reduce and even eliminate spore germination and AM colonization. Increasing $\mathrm{Zn}$ and $\mathrm{Cd}$ could reduce AM fungal spore germination and hyphal growth (33) and subsequently reduce or even eliminate AM infection (15).In the present study, for a particular plant species, root colonization, spore density were higher in non -contaminated soils (Garden soil) compared to metal contaminated soils (Shastri park soil).Further the results indicate a definite correlation between level of mycorrhizal infection in the roots and the spore counts of the soil s around them. The more is the number of spores in the rhizosphere soil, the more is the degree of colonization.

\section{Tables And Figures}

Table-1: \% colonized roots and AM fungal (AMF) spore number in rhizosphere soil and non rhizosphere soil collected from different localities in and around Delhi.

\begin{tabular}{|c|c|c|c|c|c|}
\hline $\begin{array}{c}\text { Type of } \\
\text { soil }\end{array}$ & Plant sp. & $\begin{array}{l}\text { \% root } \\
\text { coloniz-ation }\end{array}$ & $\begin{array}{l}\text { Spore no in } \\
\text { rhizosphere soil }\end{array}$ & $\begin{array}{l}\text { Spore no in non } \\
\text { rhizosphere soil }\end{array}$ & AM fungi species \\
\hline \multirow{2}{*}{$\begin{array}{l}\text { Shastri park } \\
\text { soil }\end{array}$} & Prosopisjuliflora & ---- & ---- & --- & \multirow[b]{2}{*}{$\begin{array}{l}\text { Glomusfasciculatum, } \\
\text { Acualosporalaevis }\end{array}$} \\
\hline & Cynadon sp. & 5 & 10 & 0 & \\
\hline \multirow{2}{*}{ Garden soil } & Crysantha-mum & 98 & 223 & 117 & \multirow{2}{*}{$\begin{array}{l}\text { Glomus. fasciculatum, Glomus. } \\
\text { macrocarpum, G. mossae, } \\
\text { constrictum, G. fugianum }\end{array}$} \\
\hline & Sunflower & 82.3 & 210 & 115 & \\
\hline
\end{tabular}

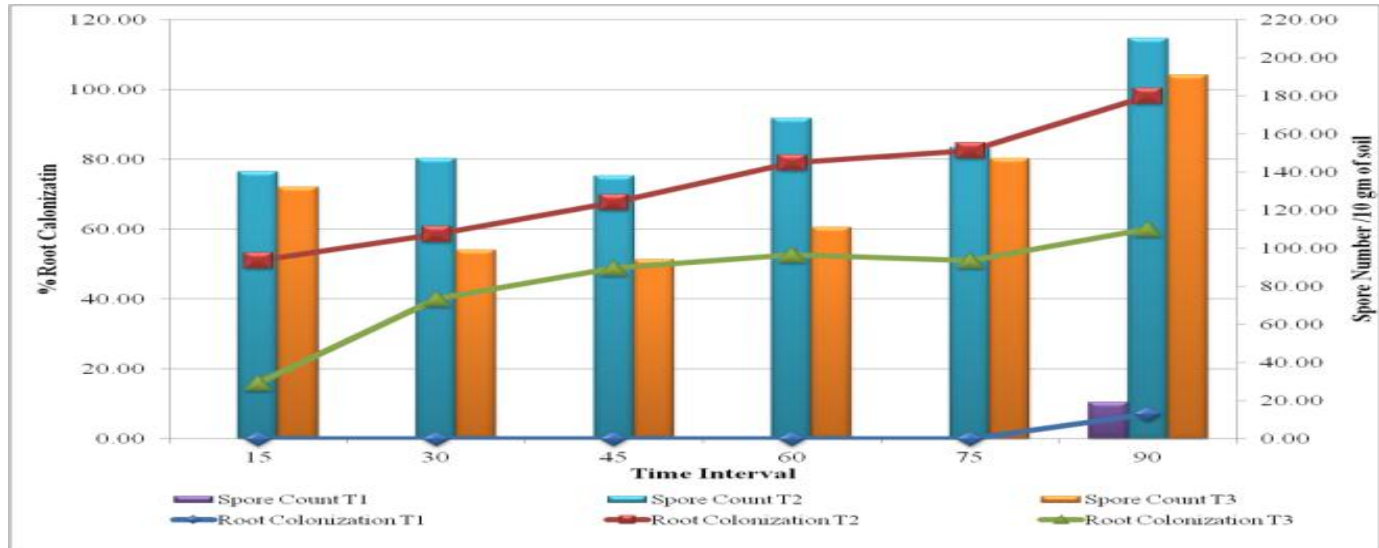

Figure 1-Mean of \% colonized roots and VAM fungal spore number (Spore count) in experimental plots soil at regular interval 

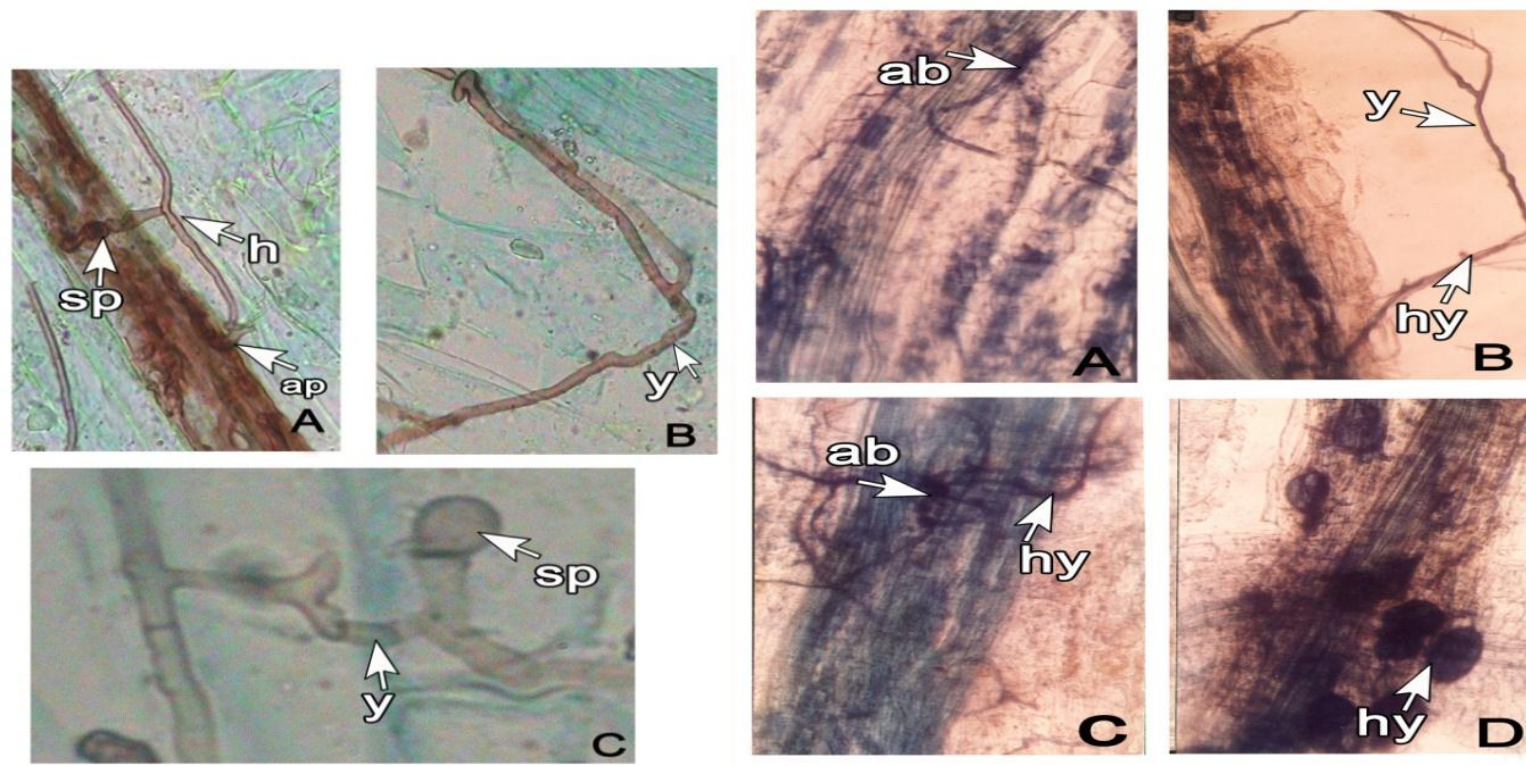

Plate I-Showing arbuscularmycorrhizal fungal components in macerated root sections of different plants species collected from contaminated and Non contaminated soil.
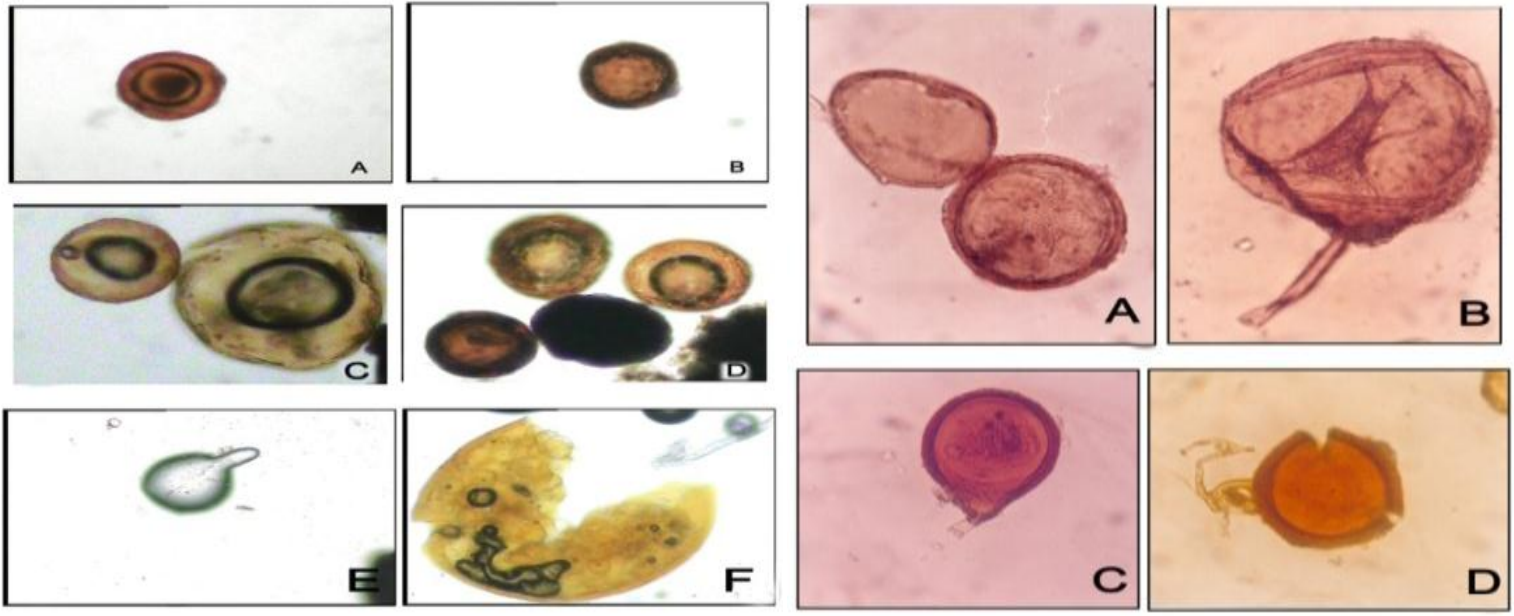

Figure 1

Figure 2

Plate II-Showing some important arbuscularmycorrhizal fungal spores recovered from rhizosphere of contaminated soil (Fig 2) and Non contaminated soil (Fig 1)

\section{Conclusion}

In the present study, five species of arbuscularmycorrhizal fungi were reported from non contaminated site and one from metal-contaminated site and thatspecies richness was higher in non contaminated site. The root colonization and spore density of AM fungi in the present study was higher in plnts inoculated with AMF inocula with stat culture extracted from non contaminated site compared to contaminated site.Test plants exhibiting potential adaptation and metal tolerance. Diversity of arbuscularmycorrhizal fungi in cadmium-rich soils is reported for the first time in India.One innovative technique is the ready- and easy-to-use inoculum in which fungal propagules are extracted from growing media. The Vetiver grass had a high tolerance to Cd. It can grow in various soil types (Sand and Clay; abundant and poor organic matter) with high Cd level in soil. The heavy metal accumulation between shoots and roots of Vetiver grass for $\mathrm{Cd}$ is $<13.2 \%$. Therefore important implication of these findings is that Vetiver can be used for phytostabalization of $\mathrm{Cd}$ on sites contaminated with high levels of heavy metals.

\section{Acknowledement}

The authors are thankful to the Department of Botany,University of Rajasthan and University of Delhi for providing necessary laboratory facilities. We gratefully acknowledge the Department of Environmental 
studies, University of Delhi, New Delhi, for helping us to analyze the samples for heavy metals. We are thankful to ShriAurobindo College for moral support and encouragement.

\section{References}

[1]. Abott,L.K. and Robson, A.D, 1991. Aquantitative study of the spores and anatomy of mycorrhizas formed by a species of Glomus, with refrence to its taxonomy. Aust. J. Bot.27: 363-375.

[2]. Barea, J. M., C. Azcón-Aguilar, and R. Azcón. 1997. Interactions between mycorrhizal fungi and rhizosphere microorganism within the context of sustainable soil-plant systems, p. 65-77. In A. C. Gange and V. K. Brown (ed.),

[3]. Birch, L. D., and R. Bachofen. 1990. Effects of microorganisms on the environmental mobility of radionucleides, p. 483-527. In J. M. Bollang and G. Stozky (ed.), Soil biochemistry, vol. 6. Marcel Dekker, New York, N.Y.

[4]. Brooks, P. C., C. Heijnen, S. P. McGrath, and E. D. Vance.. Soil microbial biomass estimates in soils contaminated with metals. Soil Biol. Biochem.18,1986,345-353.

[5]. Bundrett, M. C., N. Ashwath, and D. A. Jasper. Mycorrhizas in the Kadau region of tropical Australia. II. Propagules of mycorrhizal fungi in disturbed habitats. Plant Soil184, 1996, 173-184.

[6]. Chaudri, A. M., S. P. McGrath, K. E. Giller, E. Rietz, and D. Sauerbeck. Enumeration of indigenous Rhizobiumleguminossarumbiovartrifoliiin soils previously treated with metal sewaged sludge. Soil Biol. Biochem. 25,1993,301309.

[7]. da Silva G.A., Trufem, S.F., Saggin Junior, O.J., and Maia LC. Arbuscularmycorrhizal fungi in a semiarid copper mining area in Brazil. Mycorrhiza 15, 2005,47-53.

[8]. D1'az, G., C. Azco'n-Aguilar, and M. Honrubia., Influence of arbuscularmycorrhizae on heavy metal (Zn and Pb) uptake and growth of Lygeumspartumand Anthilliscytisoides. Plant Soil180, 1996, 241-249.

[9]. Gerdemann, J. W. and Nicolson, T. H,A Spores of MycorrhizalEndogone species extracted from soil by wet sieving and decanting technique. Trans. British Mycol. Soc., 46, 1963, 235-243.

[10]. Hayman, D.S.,Barea, J.M. and Azcon, R. Vesicular arbuscularmycorrhiza in southern spain: its distribution in crops growing in soils of different fertility. PhytopathologiaMediterranea 13, 1976, 1-6.

[11]. Jacobson, I.and Nielson, N.F. Vesicular arbuscularmycorrhizas in field grown crops I. Mycorrhizal infection in cereals and peas at various soil depths. New Phytol.93, 1983, 401-413.

[12]. Jagpal, R. and Mukerji, K.G. Distribution of VA mycorrhizal association in old Delhi Ridge. Mycorrhiza Round Table. Proceedings of a workshop held in New Delhi, 1987, 257-267.

[13]. Jasper, D. A., L. Abott, and A. D. Robson. The effect of soil disturbance on vesicular arbuscularmycorrhizal fungi in soils from different vegetation types. New Phytol. 118, 1991, 471-476.

[14]. Jensen, A. and Jacobson, I. The occurrence of Vesicular arbuscularmycorrhiza in barley and wheat grown in some Danish soils with different fertilizer treatments. Plant soil 55, 1980, 403-414.

[15]. Koomen, I., McGrath, S. P. and Giller, K. E., Mycorrhizal infection of clover is delayed in soils contaminated with heavy metals from past sewage sludge applications. Soil Biol. Biochem., 22, 1990, 871-873.

[16]. Loth, C. Abundance of arbuscularmycorrhizal fungi spores at different native sites in dependence of sludge applications. Bodenkultur47, 1996, 89-96.

[17]. McGrath, S. P., A. M. Chaudri, and K. E. Giller. 1995. Long-term effects of metals in sewage sludge on soils, microorganisms and plants. J. Ind. Microbiol.14, 1995, 94-104

[18]. Morton JB ,Three new species of Acaulospora(Endogonaceae) from high-aluminium, low pH soils in West Virginia. Mycologia, 78, 1986,641-648.

[19]. Mosse B,Mycorrhiza in a sustainable agriculture. Biol. Agric. Hort. 3, 1986, 191-209.

[20]. Pawlowska, T.E., Chaney, R.L., and Chin, M, et al., Effects of metal phytoextraction practices on the indigenous community of arbuscularmycorrhizal fungi at a metal-contaminated landfill. Applied and Environmental microbiology, 66 (6), 2000, 2526-2530

[21]. Phillips, J. M. and Hayman, D. S., Improved procedures for clearing roots and staining parasitic and vesicular arbuscularmycorrhizal fungi for rapid assessment of infection. Trans. British Mycol. Soc., 55, 1970, 158-161.

[22]. Read, D.J., Mycorrhizae in ecosystems. Experientia 47, 1991, 376-391.

[23]. Sanders, F.E. and Tinker, P.B. Mechanism of absorption of phosphate from soil by Endogonemycorrhizas. Nature 233, 1971, 278279.

[24]. Smith, S.E. and Walker, N.A. A quantitative study of mycorrhizal infection in Trifolium: separate determination of the rates of infection and of mycelial growth. New Phytol. 89, 1981, 225-240.

[25]. Smith S.E., Read D.J, Mycorrhizal Symbiosis. New York, USA: Academic Press.2008

[26]. Smith, S.E. and Read, D.J., Mycorrhizal Symbiosis. Academic Press, London, pp.605, 1997

[27]. Strzemska, J. Mycorrhiza in farm crops grown in monoculture. In “Endomycorrhizas” (Eds. F. E. Sanders, B. Mosse and P.B. Tinker) pp. 527-535. Academic press, New York, 1975

[28]. Trappe, J. M., Phylogenic and ecological aspects of mycotrophy in the angiosperms from an evolutionary stand point. In: Ecophysiology of Vesicular ArbuscularMycorrhizal Plants. Ed. Safir G., C. R. C. Press, Boca, Raton, pp.5-25. Karnataka J. Agric. Sci.,24 (3), 1987, 2011.

[29]. Vallino, M., Massa, N., Lumini, E., Bianciotto, V., Berta, G., \&Bonfante, P, Assessment of arbuscularmycorrhizal fungal diversity in roots of Solidagogigantea growing in a polluted soil in Northern Italy. Environmental Microbiology, 8(6),2006, 971-983.

[30]. Vestbery M, Occurrence of some Glomalesin Finland. Mycorrhiza 5, 1995, 329- 336.

[31]. Wang CL, JSM Tschen, and CL Wang, Factors on the spore germination of arbuscularmycorrhizal fungi, Glomusspp. Fungal Science. 12,1997,3-4.

[32]. Weissenhorn I, GlashoVA, Leyval C, Berthelin J., Differential tolerance to Cd and Zn of arbuscularmycorrhizal (AM) fungal spores isolated from heavy metal-polluted and unpolluted soils. Plant Soil167,1994,189-196.

[33]. Weissenhorn, I., C. Leyval, and J. Berthelin. Cd-tolerant arbuscularmycorrhizal (AM) fungi from heavy-metal polluted soils. Plant Soil 157, 1993, 247-256. 